\title{
Visfatin levels are decreased in advanced stages of diabetic nephropathy
}

Kathryna F. Rodrigues, Nathália T. Pietrani, Adriana A. Bosco, Cláudia N. Ferreira, Valéria C. Sandrim \& Karina B. Gomes

To cite this article: Kathryna F. Rodrigues, Nathália T. Pietrani, Adriana A. Bosco, Cláudia N. Ferreira, Valéria C. Sandrim \& Karina B. Gomes (2015) Visfatin levels are decreased in advanced stages of diabetic nephropathy, Renal Failure, 37:9, 1529-1530, DOI: 10.3109/0886022X.2015.1074520

To link to this article: https://doi.org/10.3109/0886022X.2015.1074520

册 Published online: 31 Aug 2015.

Submit your article to this journal $\pi$

Џ Article views: 239

View Crossmark data ¿

Citing articles: 1 View citing articles $\longleftarrow$ 


\title{
LETTER TO THE EDITOR
}

\section{Visfatin levels are decreased in advanced stages of diabetic nephropathy}

\author{
Kathryna F. Rodrigues ${ }^{1}$, Nathália T. Pietrani ${ }^{1}$, Adriana A. Bosco ${ }^{2}$, Cláudia N. Ferreira ${ }^{3}$, Valéria C. Sandrim ${ }^{4}$, and \\ Karina B. Gomes ${ }^{1,5}$

\begin{abstract}
${ }^{1}$ Instituto de Ciências Biológicas, Universidade Federal de Minas Gerais, Belo Horizonte, Minas Gerais, Brazil, ${ }^{2}$ Santa Casa de Belo Horizonte, Belo Horizonte, Minas Gerais, Brazil, ${ }^{3}$ Colégio Técnico - COLTEC, Universidade Federal de Minas Gerais, Belo Horizonte, Minas Gerais, Brazil, ${ }^{4}$ Instituto de Biociências, Universidade Estadual Paulista Júlio de Mesquita Filho, Botucatu, São Paulo, Brazil, and ${ }^{5}$ Faculdade de Farmácia, Universidade Federal de Minas Gerais, Belo Horizonte, Minas Gerais, Brazil
\end{abstract}

Visfatin, also known as nicotinamide phosphoribosyltransferase or pre-B-cell colony-enhancing factor 1 , is a ubiquitous adipokine firstly described in 2005 by Fukuhara et al. ${ }^{1}$ The visfatin is upregulated in visceral fat of both humans and mice and have insulin-mimetic effects by direct binding to insulin receptor, leading to glucose uptake. In addition to adipocytes, skeletal muscle, bone marrow, hepatocytes, lymphocytes, and mesangial cells can produce visfatin. ${ }^{2}$ Higher visfatin levels have been associated with obesity, type 2 diabetes mellitus (T2DM) and insulin resistance. ${ }^{3-5}$ Furthermore, visfatin acts as an inductor of the production of proinflammatory cytokines (IL-6, IL-1 $\beta$, TNF- $\alpha$ ) and reactive oxygen species generation. ${ }^{6}$ Diabetic nephropathy (DN) is a common cause of chronic kidney disease (CKD) and is associated with the increased morbidity and premature mortality in diabetic patients. $^{7}$ CKD is associated with an abnormal high adipokines level that may be caused by increased fat tissue production and/or reduced renal clearance of them. ${ }^{8}$ Recent studies showed that visfatin levels are changed in CKD (DN or not) in parallel to the glomerular dysfunction, severity of proteinuria and endothelial dysfunction. ${ }^{9-12}$ We investigated the association between visfatin levels and stages of CKD in T2DM patients with DN and the correlations with anthropometric and laboratory parameters. Thirty-eight patients [33 women and 5 men; age $59.7 \pm 6.5$ years; body mass index (BMI) $27.5 \pm 4.4 \mathrm{~kg} / \mathrm{m}^{2}$; waist circumference $97.9 \pm 12.3 \mathrm{~cm}$; serum creatinine $0.9(0.6) \mathrm{mg} / \mathrm{dL}$; blood urea $37.5(19.0) \mathrm{mg} /$ dL] were recruited from Santa Casa Hospital (Belo Horizonte, Minas Gerais, Brazil) in the period of June 2012-September 2013. Subjects older than 70 years, with cancer or autoimmune disease, with current or recent infectious process, with history of cardiovascular disease, and with treatment of anti-inflammatory drugs were excluded. T2DM

Address correspondence to Karina B. Gomes, Faculdade de Farmácia, Universidade Federal de Minas Gerais, Av. Antônio Carlos, 6627, Pampulha, Belo Horizonte, Minas Gerais 31270-901, Brazil. Tel/Fax:

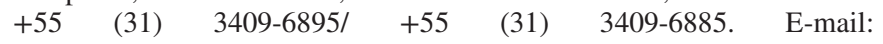
karinabgb@gmail.com diagnosis was based on the American Diabetes Association criteria. ${ }^{7} \mathrm{DN}$ was defined as albumin excretion rate $>30 \mathrm{mg} /$ $24 \mathrm{~h}$ at least 2 of 3 specimens collections within a 3- to 6month, and without coexisting renal diseases from causes other than diabetes. ${ }^{7}$ According to National Kidney Foundation (NKF), CKD was classified based on glomerular filtration ratio (GFR), estimated by Cockcroft-Gault equation: ${ }^{13,14}$ stage 1 (GFR $\left.\geq 90 \mathrm{~mL} / \mathrm{min} / 1.73^{2}\right)$, stage 2 (GFR 60 $89 \mathrm{~mL} / \mathrm{min} / 1.73^{2}$ ), stage $3\left(\right.$ GFR $\left.30-59 \mathrm{~mL} / \mathrm{min} / 1.73^{2}\right)$, stage 4 (GFR $15-29 \mathrm{~mL} / \mathrm{min} / 1.73^{2}$ ) and stage 5 (GFR $<15 \mathrm{~mL} / \mathrm{min} /$ $1.73^{2}$ or dialysis). The concentrations of visfatin (Human/ Mouse/Rat Visfatin EIA Kit, Ray Biotech Inc., Norcross, GA) were measured in serum samples by ELISA, according to the manufacturer's instructions. All samples were assayed at the same time. The concentrations of visfatin were expressed in $\mathrm{ng} / \mathrm{L}$. Anthropometric and laboratory data were obtained from medical records. The study was approved by the Ethics Committee of the Federal University of Minas Gerais and Santa Casa Hospital. Informed consent was obtained from all the patients. The T2DM patients were classified in stage 2 $\left[n=11\right.$; GFR $\left.71.94(15.94) \mathrm{mL} / \mathrm{min} / 1.73^{2}\right]$, stage $3[n=21$; GFR $\left.49.01(15.69) \mathrm{mL} / \mathrm{min} / 1.73^{2}\right]$, and stage $4[n=6$; GFR $\left.18.39(8.86) \mathrm{mL} / \mathrm{min} / 1.73^{2}\right]$. Visfatin levels were different between the CKD stages [stage 2-34.06 (56.59) ng/L; stage 3-21.25 (27.74) ng/L; stage 4-19.57 (14.51) ng/L; $p=0.042$-Kruskal Wallis' test); but this difference was significant only when compared the stage 2 versus stage 4 $(p=0.015$-Mann Whitney's test) (Figure 1). These findings were independent of fasting glucose and HbAlc levels, as well as comorbidities-retinopathy, arterial hypertension and dyslipidemia ( $p>0.05$ for all). Contrary to expected, visfatin levels were not associated with BMI categories $(\mathrm{BMI}<25$, $25 \leq \mathrm{BMI}<30$ and $\left.\mathrm{BMI} \geq 30 \mathrm{~kg} / \mathrm{m}^{2}\right) \quad(p=0.247$-Kruskal Wallis' test). Furthermore, visfatin levels showed significant correlations with GFR $(r=0.389, p=0.016)$ and serum creatinine $(r=-0.402, p=0.012)$. Taken together, our data suggest that CKD progression is associated with lower visfatin levels, independently of adiposity. This finding is contradictory to some previous studies, ${ }^{9,11,12}$ which suggested 


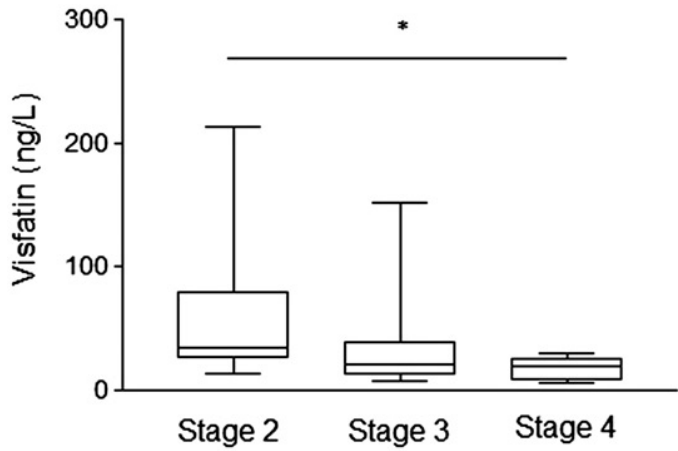

Figure 1. Visfatin levels for Type 2 diabetes mellitus patient and different stages of CKD (Kruskal Wallis' test, $* p<0.05$ ).

an increased visfatin levels due to a decline in GFR. It is important to note that these studies evaluated different groups of patients with CKD, such as glomerulonephritis, polycystic kidney disease, vasculitis and malignant hypertension; while others just compared diabetic and control group without to consider nephropathy stages, which may affect the results. Since it is known that visfatin can be produced in glomerular mesangial cells, ${ }^{2}$ but not whether visfatin levels can itself influence the renal damage progression, our results are preliminary and suggest two hypotheses: (1) the CKD progression in T2DM increases the urinary excretion of visfatin, reducing its plasma concentration; or (2) advanced stages of DN reduce local synthesis of visfatin by mesangial cells, decreasing its plasma levels. The main limitations of this study are absence a control group and a small sample size. However, as the role of visfatin levels in DN is still not clear, further studies are needed to better elucidate this association and to evaluate the potential of visfatin as a laboratory marker of nephropathy progression.

\section{Acknowledgments}

V.C.S. and K.B.G. are grateful to CNPq Research Fellowship (PQ). The authors thank FAPEMIG, CAPES, $\mathrm{CNPq} / \mathrm{Brazil}$, and PRPq/UFMG for financial support.

\section{Declaration of interest}

The authors report no conflicts of interest. The authors alone are responsible for the content and writing of the paper.

\section{References}

1. Fukuhara A, Matsuda M, Nishizawa M, et al. Visfatin: a protein secreted by visceral fat that mimics the effects of insulin. Science. 2005;307:426-430.

2. Song HK, Lee MH, Kim BK, et al. Visfatin: a new player in mesangial cell physiology and diabetic nephropathy. Am J Physiol Renal Physiol. 2008;295:F1485-F1494.

3. Berndt J, Klöting N, Kralisch S, et al. Plasma visfatin concentrations and fat depot-specific mRNA expression in humans. Diabetes. 2005;54:2911-2916.

4. Chen MP, Chung FM, Chang DM, et al. Elevated plasma level of visfatin/pre-B cell colony-enhancing factor in patients with type 2 diabetes mellitus. J Clin Endocrinol Metab. 2006;91:295-299.

5. Sandeep S, Velmurugan K, Deepa R, Mohan V. Serum visfatin in relation to visceral fat, obesity, and type 2 diabetes mellitus in Asian Indians. Metabolism. 2007;56:565-570.

6. Moschen AR, Kaser A, Enrich B, et al. Visfatin, an adipocytokine with proinflammatory and immunomodulating properties. J Immunol. 2007;178:1748-1758.

7. American Diabetes Association. Standards of medical care in diabetes - 2012. Diabetes Care. 2012;35:S11-S63.

8. Briffa JF, McAinch AJ, Poronnik P, Hryciw DH. Adipokines as a link between obesity and chronic kidney disease. Am J Physiol Renal Physiol. 2013;305:F1629-F1636.

9. Axelsson J, Witasp A, Carrero JJ, et al. Circulating levels of visfatin/pre-B-cell colony-enhancing factor 1 in relation to genotype, GFR, body composition, and survival in patients with CKD. Am J Kidney Dis. 2007;49:237-244.

10. Mahmood N, Junejo AM, Jamal Q, Awan R. Association of visfatin with chronic kidney disease in a cohort of patients with and without diabetes. J Pak Med Assoc. 2010;60:922-926.

11. Bessa SS, Hamdy SM, El-Sheikh RG. Serum visfatin as a nontraditional biomarker of endothelial dysfunction in chronic kidney disease: an Egyptian study. Eur J Intern Med. 2010;21:530-535.

12. Eyileten T, Sonmez A, Saglam M, et al. Effect of reninangiotensin-aldosterone system (RAAS) blockade on visfatin levels in diabetic nephropathy. Nephrology (Carlton). 2010;15: 225-259.

13. Cockcroft DW, Gault MH. Prediction of creatinine clearance from serum creatinine. Nephron. 1976;16:31-41.

14. Levey AS, Coresh J, Balk E, et al. National Kidney Foundation practice guidelines for chronic kidney disease: Evaluation, classification, and stratification. Ann Intern Med. 2003;139:137-147. 